\title{
Expatriate Managers: Powerful Or Powerless?
}

Roger C. Russell, Atlantic Baptist University, Canada

Catherine Aquino-Russell, University of New Brunswick, Canada

\begin{abstract}
This presentation will focus on expatriate managers for whom successful cross-cultural adjustment is imperative in overall effectiveness during overseas postings. Unfortunately, employers often blame the individual when assignments fail rather than taking responsibility themselves (Deresky 2002; Hodgetts \& Luthans 2006; Swaak 1995; Tung 1987). A study of Canadians employed in international non-government organizations in Indonesia will be presented. This research focussed on describing the lived experience of these managers using their own words. Written descriptions were analyzed/synthesized using Giorgi's descriptive phenomenological method (Giorgi 1975; 1985; Giorgi \& Giorgi 2003). One of the research findings was the paradoxical feelings of powerfulness/powerlessness as experienced by the participants. Intriguingly, the expatriate manager's position as foreigner (readily identified through 'observable differences'), brings power and status, but also feelings of being powerless in certain situations. At the same time, awareness of one's 'minority status' in combination with the large cultural differences between Canadians and Indonesians provides a potent and challenging lived experience for the expatriates (Mendenhall \& Wiley 1994). The new knowledge uncovered may result in alterations of present international human resource management practices and strategies in relation to expatriation, thereby improving the performance of expatriates and organizations.
\end{abstract}

\section{INTRODUCTION}

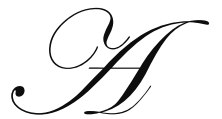

growing number of expatriates engage in worldwide activities that result in contact with different cultures. Unfortunately, not all is perfect in the expatriate world, a reality of concern for all organizations that manage expatriates. The concern stems from the fact that often "ineffective expatriate performance and premature returns have been found to relate primarily to an inability to adjust to the foreign environment" (Andreason, 2003, p.42).

Interestingly, Osland (1995a, p.xv) pointed out that "most HR managers have never lived abroad, and some mistakenly treat expatriates as if they were no different from domestic employees". It has also been said that expatriate managers "have, and their management involves, issues and problems that go beyond those of most other employees ... yet we know less about expatriates and the management of expatriates than we do about other employees" (Brewster, 2002, p.128).

This paper is based on research that was developed as a phenomenological study designed to give expatriate managers an opportunity to describe what life is like for them. The findings will enhance the understanding of human resource managers, particularly those who have never lived the experience, and will be cause for reflection of expatriate strategies and practices in use by organizations for supporting expatriate managers.

The findings from this qualitative research, using Giorgi's (1970; Giorgi \& Giorgi, 2003) descriptive phenomenological method, were eight paradoxical experiences that were described by persons who have lived the experience of being immersed in another culture. The paradox highlighted in this paper is the lived experience of feelings of powerfulness/powerlessness. It is expressed as follows: Foreigner status and feelings of powerfulness are present as a result when being immersed in another culture; however, observable differences give rise to feelings of powerlessness, vulnerability, self-consciousness and being judged by others. 


\section{LITERATURE REVIEW}

While expatriation research has increased over the past two decades (Mendenhall, Kuhlmann, Stahl, \& Osland, 2002), scholars have relied on positivistic research methodologies (Landis \& Wasilewski, 1999; Mendenhall, 1999). There is little work completed on the subjective nature of the expatriate experience (Osland, 1995b) and a . definite "shortage of qualitative studies focusing on the situated individual's experience of expatriation" (Richardson \& McKenna, 2002, p.68). A foremost researcher in expatriation, Mendenhall (1999) believed that studying expatriation through the lens of alternative paradigms would capture important insights and result in a more comprehensive understanding of the expatriate experience.

A qualitative researcher, Osland (1995a; 1995b; 2000) described how paradoxes are familiar experiences of expatriates, although paradoxes have been rarely empirically studied. Osland (1995b, p.50) described the concept of expatriate paradox: "paradoxes occur because expatriates are mediating between two cultures and two organizations".

Many Canadian employers have operations located in Indonesia and numerous Canadians are employees of these various organizations. Despite general knowledge that "doing business in Indonesia will undoubtedly be different than it is in Canada" (Farry, Jasin, Soma, \& Tobing, 1995, p.9), many international organizations expect expatriate managers to hit the ground running or at least within a matter of weeks (Forster, 2000). This seems unreasonable considering the process of making productive partnerships means immersion in the Indonesian culture and this implies time consuming adjustments in paradoxical circumstances (Suutari \& Brewster 2001; Richards 1996).

To more fully understand expatriation, it was essential to obtain the expatriate managers' own thoughts of their lived experiences being immersed in the Indonesian culture. According to the literature, lived experience is the world as persons directly experience it and describe it in their descriptions (van Manen, 1990). It is a very significant phenomenon for study as pointed out by Keen $(1975$, p.21) who said that "the lived experience must be our guide in understanding other people and what things mean to them".

\section{METHODOLOGY}

The research employed Giorgi's descriptive phenomenological method (Giorgi \& Giorgi, 2003) for utilizing and interpreting descriptions obtained from the research participants. A qualitative methodology was selected because it provided the opportunity for the research participants to describe their own personal experiences of being immersed in the Indonesian culture.

Giorgi's descriptive phenomenological method was developed for the purpose of discovering and articulating "meanings being lived by the research participants that reveal the nature of the phenomenon being researched" (Giorgi \& Giorgi, 2003, p.252). Giorgi believed that a written or verbal description of a situation could form the basis of a research study when the meaning of these descriptions is the focus rather than the seeking of objective facts. When using the phenomenological method, the researcher minimizes the distortion of the language of the research participants from the actual dialogues or written responses by dwelling with the material, by immersing oneself with the whole experience. Giorgi's method is a systematic way to uncover and discover the meaning of the lived experience (van Manen, 1990) of research participants who have experienced the phenomenon being researched. The method includes specific ways of formulating research questions and explicit procedures for data collection and analysis/synthesis, as well, guidelines for participant sampling. As evidenced in the literature (Aquino-Russell 2003; Baker, Arsenault \& Gallant, 1994; Hetherington 2002; Kraynie 1985; Ng \& Sinclair 2002; Purola \& Aavarinne 2001; Russell 2006), Giorgi's method generally provides rich data descriptions and insight into the unique experiences of persons who have lived the phenomenon under study. 


\section{SAMPLING AND RESEARCH PARTICIPANT SELECTION}

The study involved 15 research participants who were "selected purposefully to permit inquiry into and understanding of [the expatriation] phenomenon in depth" (Patton, 2002, p.46). Silverman (2000, p.104) argued that "purposeful sampling allows us to choose a case because it illustrates some feature or process in which we are interested". A good participant has the experience the researcher is studying, has the ability to reflect, is articulate, and is willing to take part in the study (Denzin \& Lincoln, 1998). The participants were chosen on the basis that they were Canadian expatriate managers, had experience with the phenomenon of being immersed in the Indonesian culture, had worked for an NGO while living in Indonesia, had lived and worked in Indonesia for more than two years, could read and write in the English language, and had a willingness to correspond with the researcher using email. To maintain anonymity, pseudonyms, chosen by the research participants, are used instead of real names in any reference in this paper.

\section{DATA COLLECTION/ANALYSIS}

"The most straightforward way to go about ... research is to ask selected individuals to write their experiences down" (van Manen, 1990, p.63). Thus, in this study, data in the form of written descriptions were collected from 15 research participants. This allowed the researcher to capture the descriptions precisely and in their entirety with no chance of imprecision as a result of transcription procedures. To initiate the actual data collection, each participant was asked to respond to the interrogatory statement: 'Please write about an experience or situation that best describes what it was like for you to live and work as an expatriate manager in Indonesia'. The statement was planned to draw out, without leading, the feelings and thoughts of expatriate managers and participants were left to write as much, or as little, as they deemed appropriate. Following acceptance of the research participants' written descriptions, the researcher then undertook Giorgi's process (summarized by Aquino-Russell (2003)) as described in Table 1.

Table 1

Giorgi's Descriptive Phenomenological Method

Step 1 -Dwelling with the written description

This involved the researcher engaging in a rigorous process of intuiting, analyzing, and describing the raw data descriptions which was completed through reading and rereading the entire description of each participant's experience to get a general sense of the whole.

Step 2 - Identifying Meaning Units slash was placed in the description of the text (Giorgi, 1989). The researcher operated with spontaneity while constituting meaning units (thinking: something important is happening here or there is a change here or something interesting is going on). By doing this, the researcher dwelled with the description longer than when it was first read (Giorgi, 1989).

\section{Step 3 - Identifying Focal Meanings}

The meaning units were raised to a higher level of discourse and were reformulated by the researcher to become focal meanings in the language of the researcher. During this part of the process, meanings were uncovered (Spiegelberg, 1971) and the analytical phase of data description interpretation was completed.

\section{Step 4 - Synthesizing Situated Structural Descriptions}

The researcher synthesized each set of focal meanings into a situated structural description for each participant. It is the situated structural description that grasps the meaning of the lived experience from the perspective of the participant. The investigator synthesized and integrated the insights contained in all of the focal meanings into a consistent statement for each of the participants' lived experience of being immersed in another culture.

Step 5 - Synthesizing a General Structural Description

The general structural description of this lived experience was generated from the synthesis of the participants' situated structural descriptions. This stage grasps the most general significance of the phenomenon under study and is aimed at capturing the meaning of the lived experience described by the participants in an insightful and focused way (Baker et al., 1994). Giorgi (1975, p.88) stated that the general structural description "leaves out the particulars of the specific situation and centers on those which ... while not necessarily universal are at least trans-situational or more than specific".

(Aquino-Russell, 2003, p.99-103) 


\section{FINDINGS}

As noted in Step 5 above, the study was carried out to answer the research question: What is the general structural description (GSD) of being immersed in another culture for expatriate managers? The answer to this question leads to a better understanding of what it is like to be an expatriate manager immersed in another culture, as well as suggestions for improvements in support of the expatriate experience. Bearing this in mind, being immersed in another culture involves living new ways of being and experiencing paradoxical feelings. It is noted that "paradoxes are not opposites, but are dimensions of the same rhythm lived all-at-once where one is in the foreground and one is in the background" (Parse, 1998, p.30).

The findings from this qualitative research, using Giorgi's (1970; Giorgi \& Giorgi, 2003) descriptive phenomenological method, included eight paradoxical experiences as lived by expatriate managers who were immersed in the Indonesian culture. One of these findings, and the primary focus of this paper, is the paradoxical feeling of powerfulness/powerlessness as experienced by the participants. This paradox is expressed as: Foreigner status and feelings of powerfulness are present as a result when being immersed in another culture; however, observable differences give rise to feelings of powerlessness, vulnerability, self-consciousness and being judged by others.

To further delineate the paradoxical feelings of powerfulness/powerlessness and this component of the GSD, selected 'clips' (or direct quotations) of the research participants' descriptions of thoughts and/or experiences are presented in Table 2 to assist the reader in following the interpretive trail from research participants' words to the findings.

Table 2

Linking Research Participants' Descriptions to Feelings of powerfulness/powerlessness and Component of GSD

\begin{tabular}{|c|c|c|}
\hline Research Participant & $\begin{array}{c}\text { Meaning } \\
\text { Unit }\end{array}$ & $\begin{array}{c}\text { 'Clips' (Direct Quotations) from Research Participants' Descriptions of Thoughts } \\
\text { and/or Experiences }\end{array}$ \\
\hline Pak Jasiento & 4 & $\begin{array}{l}\text { There we were for all to see, sitting in the second row just behind one or other of the } \\
\text { couple's parents and, we are sure, well in front of siblings, aunts and uncles! Little did } \\
\text { we understand at the time that we were part of the family's way of demonstrating their } \\
\text { social status, through their association with foreigners [a position of status, value \& } \\
\text { powerfulness] }\end{array}$ \\
\hline Pak Jasiento & 7 & $\begin{array}{l}\text { Many elaborately engraved invitations to attend weddings at lavish [big city] hotel } \\
\text { ballrooms would arrive at our home or small office from people that we barely knew } \\
\text { or in some case did not know at all (a sort of nuptial SPAM). We were advised that } \\
\text { there was no real expectation that invitations sent to 'expats', (in addition to thousands } \\
\text { of their friends and relatives), would result in a high percentage of acceptance, but it } \\
\text { was certainly worth a try. [feelings of powerlessness] }\end{array}$ \\
\hline Prunes & 4 & $\begin{array}{l}\text { I was totally embarrassed and couldn't stand the attention. [powerlessness with } \\
\text { attention] }\end{array}$ \\
\hline Prunes & 8 & $\begin{array}{l}\text { The people from the village suggested that we call in the 'dukun' and I very } \\
\text { reluctantly agreed. I was desperate. [powerlessness] }\end{array}$ \\
\hline Martin Wyatt & 19 & $\begin{array}{l}\text { I could not imagine any situation where a } 25 \text { year old Indonesian villager would have } \\
\text { convinced the people in that room to go see a doctor.... In this case it was lucky that } \\
\text { there was this kind of differentiation for foreigners. [feelings of powerfulness] }\end{array}$ \\
\hline Kate Phelan & 7 & $\begin{array}{l}\text { All around us, dozens of families were doing the same. I was the only foreign face. } \\
\text { [observable differences leads to position of powerfulness-powerlessness] }\end{array}$ \\
\hline Batman & 3 & $\begin{array}{l}\text { Having spotted a foreigner too late, they must have regretted not having negotiated a } \\
\text { higher price... I suppose it's the vulnerable exploiting the vulnerable. [feelings of } \\
\text { powerlessness] }\end{array}$ \\
\hline Justin Edwards & 10 & $\begin{array}{l}\text { It is difficult for me to do anything about this as it is related to culture norms that have } \\
\text { been established for hundreds of years. [feelings of powerlessness] }\end{array}$ \\
\hline
\end{tabular}

(Russell, 2006, p.270) 


\section{Discussing The Paradoxical Feelings Of Powerfulness/Powerlessness}

Several research participants described their elevated status as foreigners and the feelings of powerfulness or powerlessness that it entailed. Pak Jasiento described being invited to numerous weddings for people they barely knew and in some cases invitations from people they did not know at all, simply because they were foreigners. Although Pak Jasiento just wanted to blend into the crowd at a wedding he attended, he described being seated in a prime location for all to see. This served to enhance his hosts' social status but left Pak Jasiento with feelings of being used, self-conscious and vulnerable. Prunes described feelings of self-consciousness and even humiliation when reacting to the physical assault of extra spicy food in front of Indonesians.

Prunes, although in a position of power, felt powerlessness amid the local cultural milieu and in dealing with what appeared to be a serious health issue of an Indonesian co-worker, and so he reluctantly agreed to engage in the services of a 'dukun' (witch doctor). On the other hand, when Martin Wyatt was faced with a serious health issue of a fellow Canadian expatriate he felt his status as foreigner led to increased powerfulness which was not typical for Indonesians of a similar age and experience.

In Indonesia, Canadians are generally a visible minority which provides for instant identification that one is a foreigner. In Kate Phelan's example, she described her self-consciousness at being the only foreign face among a large group of Indonesians during an annual religious pilgrimage. Batman described his feelings of being vulnerable to higher pricing of goods/services simply because of his status as a Westerner and knowing there is little that can be done regarding the reality of 'observable differences'. A final example is Justin Edward's feelings of powerlessness in relation to not having the capability to change cultural norms that have been in existence for hundreds of years.

Overall, these findings point to the fact that the expatriate managers' position as foreigner, readily identified through 'observable differences', brought the research participants power and status, but also made them feel powerless in certain situations. Feelings of vulnerability and self-consciousness were experienced frequently by the research participants.

The findings serve to enhance overall knowledge in relation to the expatriates' feelings of powerfulness/powerlessness as a result of being recognized as 'foreigners' in the host culture. The current research is typical of the extant literature in that it concerns Westerners who have expatriated to other countries. Further, as is the case in the current study, these expatriates frequently are assigned to countries in the developing world where, often, they are a visible minority in addition to facing large cultural distances (Mendenhall \& Wiley 1994). The findings refer to 'observable differences' which is similar to the literature reference of 'minority status' (Mendenhall $\&$ Wiley 1994). As seen in the findings, this 'minority status' awareness of oneself in combination with the large cultural differences between Canadians and Indonesians provides a potent and challenging lived experience for the expatriates.

The findings are supported in the literature by Osland's (2000 p.233) research. She described a phenomenon called a 'marginality paradox' where expatriates generally think well of the local persons while simultaneously being very cautious so not to be taken advantage of by these same hosts. Generally, a Western expatriate 'sticks out in the crowd' in Indonesia which often is associated with feelings of vulnerability, selfconsciousness, and being judged by others. In reference to powerfulness, Osland (2000 p.233) identified a 'social acuity paradox' that has the expatriate possessing a great deal of power, yet not exercising this power in order to obtain full participation and mutual assistance from host nationals.

\section{CONTRIBUTIONS AND RECOMMENDATIONS}

In an effort to enhance understanding of being immersed in another culture, the study was designed to explore expatriate managers' perspectives of the phenomenon by identifying the reality of their lived experiences. The researcher expects understanding may lead to improvements in human resource management practices as well as strategies for facilitating and supporting the expatriation experience, thereby benefiting both the expatriate and the home organizations that employ them. The findings also have implications which apply for a wide range of interests in the expatriation field including those of academic researchers and educators, human resource 
management professionals, senior managers, and expatriates of the past, present, and future. Contributions and recommendations for human resource management practice are as follows:

\section{Human Resource Management Practice}

International human resource management (IHRM) is a critical profession in light of globalization, especially when one considers the economic growth in large countries like China and India. Combined with an increased understanding of lived experiences of expatriates, the growth and development of IHRM is an excellent opportunity for human resource professionals to assist expatriates who may be overwhelmed by the paradoxical experiences and challenges involved in being immersed in another culture, especially one like Indonesia, which is so dissimilar to their own culture. The findings have expanded on the work of Osland (1995a, p.211) who, over a decade ago, recommended that "HR departments should respond to expatriate questions and concerns immediately. Still, it is common for some departments to ignore requests by out-of-sight expatriates until the volume is cranked up to howls of outrage". Indeed, one of Osland's research participants said: "Somebody at headquarters needs to know it's tough to work abroad" (p.210).

Generally, current human resource practices relating to expatriation have been focused on the selection procedures along with pre-departure training; however, it is apparent, that expatriates are left largely to their own means and devices during the overseas assignment itself and, in fact, seemingly are forgotten until repatriation time. This is not acceptable. Thus, it is recommended that human resource professionals make frequent and regular contact with expatriates who are working overseas to find out what the experience is like for them. They need to listen and support the expatriates given the reality of extreme paradoxical experiences of those when immersed in another culture. Again, the recommendation reinforces Osland's (1995a, p.211) view that "the only way to know who needs extra help or attention is to call and check on their progress... Companies should not assume that expatriates are doing well overseas". Yet it is not about seeking to find that someone is NOT doing well, but seeking to understand what the employee's experience is like and what would be helpful to make the extremes more manageable. All persons will know what is best for them and be more confident in their work because expatriates do not wish their experiences to be harshly judged or unnecessarily criticized, especially by others who are not living the experience or not seemingly understanding the experience.

The lived experience of being immersed in another culture is a highly individualistic experience. Employees' experiences must be understood in order to enact change to enhance their lived personal and professional experiences in situations. Standardized strategies are often used at present; however, experiences may be studied more easily and challenges improved by use of regular, qualitative research methods. Persons in the home organization need to become more understanding and more aware of their own shortcomings in their relationships with expatriates. Shaffer, Harrison, \& Gilley (1999) recommended that a well-chosen mentor, who has experienced the phenomenon, can assist greatly in the overall well-being and productiveness of the expatriate. Thus, a mentor should be assigned to each overseas employee; a useful, practical and relatively cheap alternative to present-day practice.

Again, it may be helpful to be reminded that "most HR managers have never lived abroad, and some mistakenly treat expatriates as if they were no different from domestic employees" (Osland, 1995a, p.xv). Thus, it is believed by the researcher that enhanced understanding emerging from this research study has the potential to alter the way that human resource professionals choose to deal with employees on overseas postings.

\section{CONCLUSION}

In today's world, there is an ever-increasing number of persons living and working away from their home countries. Expatriates, who live away from their home country, have a wide variety of experiences and strong personal feelings during their time of being immersed in another culture. To help organizations and individuals understand the complexities of the phenomenon, exploring the experiences, feelings, and thoughts of expatriates through their descriptions of what it is like to be immersed, living and working, in another culture is important. Expatriates have a tremendous amount of knowledge to share with human resource professionals and academics, whose work will be aided with better understanding of the challenges of managing today's global work force. 
Furthermore, the shared knowledge also will help present and former expatriates to make sense of their experiences, and through education and training, provide future expatriates with valuable insights into the nature of overseas experiences.

\section{REFERENCES}

1. Andreason, A. W. (2003). Expatriate adjustment to foreign assignments. International Journal of Commerce and Management, 13(1), 42.

2. Aquino-Russell, C. E. (2003). Understanding the lived experience of persons who have a different sense of hearing. Curtin University of Technology, Perth, AU.

3. Baker, C., Arsenault, A.M. \& Gallant, G. (1994). Resettlement without the support of an ethnocultural community. Journal of Advanced Nursing, 20, 1064-1072.

4. Brewster, C. (2002). Human resource practices in multinational companies. In M. J. Gannon \& K. L. Newman (Eds.), The blackwell handbook of cross-cultural management. Oxford, UK: Blackwell Publishers Ltd.

5. Denzin, N. K., \& Lincoln, Y. S. (1998). Collecting and interpreting qualitative materials. Thousand Oaks, CA: Sage Publications.

6. Deresky, H. (2002). International management: Managing across borders and cultures (4th ed.). Upper Saddle River, NJ: Prentice Hall.

7. Farry, P., Jasin, J., Soma, S., \& Tobing, M. (1995). Working with an Indonesian partner: A guide to establish effective cross-cultural communication and working relationships in Indonesia. Hull, PQ: Canadian Foreign Service Institute Centre for Intercultural Learning.

8. Forster, N. (2000). Expatriates and the impact of cross-cultural training. Human Resource Management Journal, 10(3), 63-78.

9. $\quad$ Giorgi, A. (1970). Psychology as a human science. A phenomenologically based approach. New York: Harper \& Row.

10. Giorgi, A. (1975). An application of phenomenological method in psychology. In A. Giorgi, C. Fischer \& E. Murray (Eds.), Duquesne studies in phenomenological psychology (Vol. II). Pittsburgh: Duquesne University Press.

11. Giorgi, A. (1985). Phenomenology and psychological research. Pittsburgh: Duquesne University Press.

12. Giorgi, A. (1989). One type of descriptive data: Procedures involved in following a systematic phenomenological method. Annual Edition of Methods: A Journal for Human Science, 39-61.

13. Giorgi, A. P., \& Giorgi, B. M. (2003). The descriptive phenomenological psychological method. In P. M. Camic, J. E. Rhodes \& L. Yardley (Eds.), Qualitative research in psychology: Expanding perspectives in methodology and design. Washington, DC: American Psychological Association.

14. Hetherington, D. (2002). Disaster trauma: A phenomenological-linguistic analysis of Buffalo Creek flood accounts (West Virginia). Dissertation Abstracts International, 63 (2-B), 1029.

15. Hodgetts, R. M., Luthans, F., \& Doh, J. P. (2006). International management:

16. Culture, strategy, and behavior (6th ed.). New York, NY: McGraw-Hill/Irwin.

17. Keen, E. (1975). A primer in phenomenological psychology. New York, NY: Holt, Rinehart and Winston Inc.

18. Kraynie, L. K. (1985). The lived experience of persisting in change: A phenomenological study. In R. R. Parse, A. B. Coyne \& M. J. Smith (Eds.), Nursing research: Qualitative methods. Bowie, MD: Brady Communications.

19. Landis, D., \& Wasilewski, J. H. (1999). Reflections on 22 years of the international journal of intercultural relations and 23 years in other areas of intercultural practice. International Journal of Intercultural Relations, 23(4), 535-574.

20. Mendenhall, M. E. (1999). On the need for paradigmatic integration in international human resource management. Management International review, 39(3), 65-88.

21. Mendenhall, M. E., Kuhlmann, T. M., Stahl, G. K., \& Osland, J. S. (2002). Employee development and expatriate assignments. In M. J. Gannon \& K. L. Newman (Eds.), The blackwell handbook of cross-cultural management. Oxford, UK: Blackwell Publishers Inc.

22. Mendenhall, M. E., \& Wiley, C. (1994). Strangers in a strange land: The relationship between expatriate adjustment and impression management. American Behavioral Scientist, 37 (5), 605-620. 
23. Ng, M., \& Sinclair, M. (2002). Women's experience of planned home birth: A phenomenological study. RCM Midwives Journal, 5 (2), 56-59.

24. Osland, J. S. (1995a). The adventure of working abroad: Hero tales from the global frontier. San Francisco, CA: Jossey-Bass Publishers.

25. Osland, J. S. (1995b). Working abroad: A hero's adventure. Training \& Development, 49(11), 47-51.

26. Osland, J. S. (2000). The journey inward: Expatriate hero tales and paradoxes. Human Resource Management, 39(2,3), 227-238.

27. Parse, R. R. (1998). The human becoming school of thought. A perspective for nursing and other health care professionals. London: Sage Publications.

28. Patton, M. Q. (2002). Qualitative research \& evaluation methods (3rd ed.). Thousand Oaks, CA: Sage Publications.

29. Purola, H., \& Aavarinne, H. (2001). Phenomenologic research process in nursing science: Experiences of home dwelling stroke patients and their relatives about coping. Hoitotiede, 13 (2), 68-77.

30. Richards, D. (1996). Strangers in a strange land: Expatriate paranoia and the dynamics of exclusion. The International Journal of Human Resource Management, 7(2), 553-571.

31. Richardson, J., \& McKenna, S. (2002). Leaving and experiencing: Why academics expatriate and how they experience expatriation. Career Development International, 7(2), 67-78.

32. Russell, R. (2006). Expatriate managers' immersion in another culture: A phenomenological study of lived experiences. . Curtin University of Technology, Perth, AU.

33. Shaffer, M. A., Harrison, D. A., \& Gilley, K. M. (1999). Dimensions, determinants, and differences in the expatriate adjustment process. Journal of international Business Studies, 30(3), 557-582.

34. Silverman, D. (2000). Doing qualitative research: A practical handbook. Thousand Oaks, CA: Sage.

35. Spiegelberg, H. (1971). The phenomenological movement: A historical introduction (2nd ed. Vol. II). The Hague: Martinus Nijhoff.

36. Suutari, V., \& Brewster, C. (2001). Expatriate management practices and perceived relevance. Personnel Review, 30(5/66), 554-577.

37. Swaak, R. A. (1995). Expatriate failures: Too many, too much cost, too little planning. Compensation and Benefits Review, 27 (6), 47-55.

38. Tung, R. L. (1987). Expatriate assignments: Enhancing success and minimizing failure. The Academy of Management Executive, 1 (2), 117-126.

39. van Manen, M. (1990). Researching lived experience: Human science for an action sensitive pedagogy. London, Canada: The Althouse Press, University of Western Ontario. 